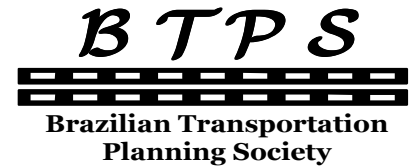

Planning Society

\author{
Journal of Transport Literature \\ Vol. 8, n. 1, pp. 210-234, Jan. 2014 \\ Research Directory
}

\section{JTL|RELIT}

www.transport-literature.org ISSN 2238-1031

\title{
Plataformas Logísticas: uma abordagem sobre as tipologias e características através de uma revisão sistemática
}

[Logistics Platforms: an approach about the typologies and characteristics through a systematic review]

\author{
Rafael Mozart da Silva*, Eliana Terezinha Pereira Senna, \\ Luiz Afonso dos Santos Senna , Orlando Fontes Lima Júnior \\ Universidade Estadual de Campinas - UNICAMP - Brasil, Universidade Estadual de Campinas - UNICAMP - Brasil, \\ Universidade Federal do Rio Grande do Sul - UFRGS - Brasil, Universidade Estadual de Campinas - UNICAMP - Brasil
}

Submitted 12 Dec 2012; received in revised form 12 Jan 2013; accepted 21 Jan 2013

\begin{abstract}
Resumo
Atualmente a constante competição dos mercados tem feito com que as organizações passem a repensar suas estratégias logísticas, sob forma de utilizar um sistema de operações logísticas que seja capaz de integrar os atores e recursos envolvidos na cadeia de suprimentos. Este trabalho teve como objetivo de pesquisa, analisar as principais tipologias e características das plataformas logísticas. A metodologia de pesquisa adotada para atingir aos objetivos da pesquisa foi baseada na revisão sistemática, pois possibilitou aos pesquisadores a elaboração e desenvolvimento do conhecimento acerca do tema plataforma logística de uma forma estruturada, clara e objetiva. Ficou evidenciando durante a pesquisa e análise dos trabalhos que a utilização de plataformas logísticas surgem como uma alternativa frente aos desafios contemporâneos, onde se faz necessário um redesenho logístico para atendimento as demandas e a transposição das restrições atuais impostas a distribuição de produtos em centros urbanos ou mesmo para responder de forma dinâmica e eficiente aos diversos elos da cadeia de suprimentos.
\end{abstract}

Palavras-Chave: plataforma logística, aldeias logísticas, parques logísticos, zona logística, revisão sistemática.

\begin{abstract}
Currently the constant competition of markets has done with the organizations start to rethink their logistics strategies in the form of using a system of logistics operations that is capable to integrate the resources and actors involved in the supply chain. This work had as objective of research analyze the main typologies and characteristics of logistic platforms. The research methodology adopted to reach the goals of the research was based on a systematic review, because it allowed to the researchers the elaboration and development of knowledge about the topic logistics platform in a structured way, clear and objective. It has become evident during the research and analysis of the works that the use of logistics platforms emerge as an alternative face to contemporary challenges, where a logistic redesign is necessary to meet the demands and transposition of the current restrictions imposed on the distribution of products in urban centers or even to respond dynamically and efficiently to the various links in the supply chain.
\end{abstract}

Key words: logistics platforms, freight village, distriparks, logístics zones, systematic review .

*Email: rafmozart@terra.com.br.

\section{Recommended Citation}

Silva, R. M. , Senna, E. T. P., Senna, L. A. D.S. and Lima Júnior, O. F. (2014) Plataformas Logísticas: uma abordagem sobre as tipologias e características através de uma revisão sistemática. Journal of Transport Literature, vol. 8, n. 1, pp. 210-234.

- JTL/RELIT is a fully electronic, peer-reviewed, open access, international journal focused on emerging transport markets and published by BPTS - Brazilian Transport Planning Society. Website www.transport-literature.org. ISSN 2238-1031.

This paper is downloadable at www.transport-literature.org/open-access. 


\section{Introdução}

A discussão sobre a temática plataforma logística mostra-se relevante no contexto contemporâneo, onde a busca por uma maior competitividade por parte das empresas ultrapassa as fronteiras locais e na esfera pública permeia os desafios em prover uma infraestrutura logística que seja capaz de suportar as demandas associadas ao desenvolvimento.

Entende-se que a busca pelo adequado entendimento sobre as principais características dos empreendimentos logísticos denominados plataformas logísticas, pode contribuir para que as organizações públicas e privadas elaborem o redesenho de suas estratégias e arranjos logísticos em busca de uma maior eficiência local e global. Ainda que este tema esteja em desenvolvimento, constata-se através de pesquisas que existem iniciativas mais concisas com relação à utilização de plataformas logísticas em países desenvolvidos e também no campo acadêmico alguns trabalhos publicados com enfoque singular sobre determinado aspecto deste tipo de empreendimento logístico.

Este artigo teve como objetivo geral analisar as principais tipologias e características das plataformas logísticas, observando as atividades e serviços realizados nestes empreendimentos logísticos. Para atingir o objetivo da presente pesquisa, foi adotada a metodologia de investigação baseada na revisão sistemática, onde se realizou consultas seguindo uma estrutura de investigação em diversas bases de dados através da Coordenação de Aperfeiçoamento de Pessoal de Nível Superior - CAPES as quais são apresentadas na Seção 2 deste trabalho. De acordo com Clarke (2001), para a realização de uma revisão sistemática da literatura devem-se utilizar métodos sistemáticos e explícitos para identificar, selecionar e avaliar criticamente pesquisas relevantes, e coletar e analisar dados de estudos incluídos na revisão.

Algumas variáveis como o aumento do consumo, a busca por uma minimização dos custos e maximização dos lucros, redução dos níveis de estoques ao longo da cadeia, melhoria no nível de serviço logístico, deficiência de infraestrutura de transportes, congestionamentos nos centros urbanos dentre outros fatores tem feito com que a iniciativa privada e o próprio poder 
público tenham a necessidade de encontrar alternativas para suportar o aumento deste dinamismo no cenário contemporâneo (Nilesh et al. 2012; Iannone, 2012).

Neste contexto, o dinamismo atual condiciona as empresas a buscarem e utilizar-se de novas formas de organização, que possam ser capazes de responder rapidamente e com flexibilidade as exigências do mercado mantendo, sobretudo a qualidade e os custos dos produtos. Neste sentido as empresas vêm pressionando os fornecedores e distribuidores para que suas operações tenham flexibilidade e sejam capazes de reduzir o tempo de ciclo do pedido. $\mathrm{Na}$ esfera pública têm-se algumas discussões como a busca de soluções relacionadas ao fluxo de veículos de cargas nas cidades, a análise da interação entre o transporte de mercadorias com o movimento de pessoas, a infraestrutura local disponível para a movimentação de cargas, os impactos ambientais e congestionamentos gerados pela logística de distribuição dentre outros aspectos (Stathopoulosa, Valeria e Marcuccib, 2012; Russo e Comi, 2011)

A utilização de uma plataforma logística, ambiente este, onde os diferentes participantes da cadeia de suprimentos estão integrados em um mesmo local físico e com isto têm a possibilidade de obter uma maior sinergia entre os diferentes processos logísticos e modais de transportes utilizados, contribuem para na melhoria do nível de serviço logístico prestado (Cambra-Fierro e Ruiz-Benitez, 2009; Pettit e Beresford, 2009).

A plataforma logística (PL) pode ser classificada como um local específico onde as atividades relativas à produção, transportes, logística e distribuição de mercadorias são realizadas, utilizando-se de uma mesma base de serviços onde os diferentes atores envolvidos se relacionam com objetivo de obter eficiência e flexibilidade em suas operações e consequentemente uma maior vantagem competitiva no mercado em que atuam (Rimienè e Grundey, 2007; Meidutè, 2007; Gajsek et al. 2012; Campolongo et al. 2010; Marte, 2012).

Na Seção 1 é apresentado o tema e uma breve contextualização do problema investigado. $\mathrm{Na}$ Seção 2, apresenta-se a metodologia e etapas do método utilizado para a realização deste trabalho, onde são definidos os principais pontos desta pesquisa. Uma síntese dos resultados obtidos com a revisão sistemática é apresentada na Seção 3. Na Seção 4, apresenta-se uma análise e discussões sobre os principais achados da pesquisa. Por fim, demonstram-se as conclusões e contribuições do trabalho, as quais poderão ser utilizadas como hipóteses para novas pesquisas. 


\section{Metodologia de Pesquisa}

A metodologia utilizada neste trabalho foi à revisão sistemática da literatura, na qual se utilizou um processo estruturado para a revisão da literatura abrangendo um planejamento, execução e análise dos dados pesquisados (Soni e Kodali, 2011; Santos Júnior et al. 2011; Biolchini et al. 2007). A realização da pesquisa ocorreu no período de março a setembro de 2012. Na Tabela 1, apresenta-se a estrutura das etapas e passos utilizados na realização desta pesquisa:

\section{Tabela 1- Estrutura básica para Revisão Sistemática ${ }^{1}$}

\begin{tabular}{|c|c|}
\hline Etapas & Passo a paso a seguir \\
\hline \multirow{4}{*}{$\begin{array}{l}1 \text { - Planejamento } \\
\text { da pesquisa }\end{array}$} & $\begin{array}{l}\text { Passo 1.1: Definir a questão de pesquisa que irá direcionar a revisão da } \\
\text { literatura. A questão de investigação deve ser clara e concisa; }\end{array}$ \\
\hline & $\begin{array}{l}\text { Passo 1.2: Definir a estratégia de pesquisa, definido quais serão as bases de } \\
\text { dados e os períodos a serem pesquisados; }\end{array}$ \\
\hline & $\begin{array}{l}\text { Passo 1.3: Definir os critérios de inclusão e ou exclusão dos trabalhos a } \\
\text { serem analisados. Nesta etapa é necessário escolher as palavras-chave que } \\
\text { sejam adequadas para a seleção dos trabalhos; }\end{array}$ \\
\hline & $\begin{array}{l}\text { Passo 1.4: Realizar uma seleção preliminar dos trabalhos de acordo com a } \\
\text { estratégia de pesquisa definida no Passo } 1.2 \text { e utilizar os critérios de } \\
\text { inclusão e ou exclusão definidos no Passo } 1.3 \text { da etapa de planejamento. }\end{array}$ \\
\hline $\begin{array}{l}2 \text { - Análise dos } \\
\text { trabalhos } \\
\text { publicados }\end{array}$ & $\begin{array}{l}\text { Passo 2.1: Realizar uma análise profunda nos trabalhos selecionados no } \\
\text { Passo 1.4, considerando obras que apresentam uma relação com a questão } \\
\text { de pesquisa. Deve-se definir categorias para classificação dos trabalhos a } \\
\text { fim de organizar a análise e a profundidade dos trabalhos consultados. }\end{array}$ \\
\hline $\begin{array}{l}3 \text { - Execução da } \\
\text { pesquisa }\end{array}$ & $\begin{array}{l}\text { Passo 3.1: Apresentar os resultados finais da análise, demonstrando os } \\
\text { autores e fontes de consulta que contribuíram para a questão de pesquisa, } \\
\text { elaborada no Passo } 1.1 \text { da etapa de planejamento. Na etapa de execução } \\
\text { apresentam-se as lacunas de pesquisa identificadas e também as } \\
\text { oportunidades para futuras pesquisas. }\end{array}$ \\
\hline
\end{tabular}

A técnica de revisão sistemática vinha sendo amplamente utilizada na área das ciências humanas, mas ao longo dos anos este tipo de técnica de pesquisa vem sendo empregada em novas áreas, reforçando a discussão de que as fronteiras pela busca do conhecimento são

\footnotetext{
${ }^{1}$ Fonte: elaborada pelos autores.
} 
amplas e multidisciplinares (Soni e Kodali, 2011; Tranfield, Deyer e Smart, 2003; Biolchini et al. 2007; Santos Júnior et al. 2011).

\subsection{Estruturação da Revisão Sistemática}

Para a realização da investigação acadêmica de um problema de pesquisa específico, torna-se necessário seguir uma estrutura de trabalho rígida. A utilização da revisão sistemática permite ao pesquisador mapear e avaliar o território intelectual disponível a fim de tornar o conteúdo encontrado mais consistente e aderente a questão de pesquisa (Tranfield, Deyer e Smart, 2003). Para a aplicação da revisão sistemática como forma de pesquisa, foi seguida a estrutura proposta na Tabela 1, a qual compreendeu as etapas de planejamento, análise e execução.

A primeira etapa da revisão sistemática compreende o planejamento da pesquisa, conforme segue abaixo:

- Passo 1.1: A definição da questão de pesquisa compreende uma etapa importante do trabalho, pois é a partir deste questionamento que se busca obter respostas ao problema investigado. A questão de pesquisa elaborada foi: Quais as principais características e tipologias das plataformas logísticas? A questão de pesquisa proposta foi realizada de forma mais abrangente, pois havia a intenção de possibilitar aos pesquisadores investigar também dentro da temática plataforma logística quais as oportunidades de futuras pesquisas acadêmicas pertinentes a este tipo de empreendimento logístico.

- Passo 1.2: A qualidade e confiabilidade das fontes de consulta dos materiais a serem pesquisados e analisados apresentam-se como uma variável importante e também relevante para a realização da revisão sistemática. Para a realização deste trabalho foram realizadas pesquisas na base de periódicos da Coordenação de Aperfeiçoamento de Pessoal de Nível Superior - CAPES utilizando a busca avançada por assunto através do acesso VPN (virtual private network), que consiste na criação de um túnel de comunicação criptografado entre o computador e o servidor VPN da instituição, provendo um acesso seguro à rede da Universidade Estadual de Campinas UNICAMP. As bases de dados consultadas foram: Academic Search Premier - ASP (EBSCO); Cambridge Journals Online; Oxford Journals (Oxford University Press); 
ScienceDirect (Elsevier); SpringerLink (MetaPress); Wiley Online Library; ACM Digital Library; ACS Journals Search; Emerald Fulltext (Emerald), OneFile (GALE) e IEEE Xplore.

- Passo 1.3: Após uma pesquisa prévia na literatura as palavras chaves foram escolhidas as seguintes palavras-chave: "Platforms logistics", "Logistics Platforms", "Distripark", "Distriport" e "Freight Village". O idioma escolhido para a pesquisa foi o inglês, em razão da amplitude e também por ser universalmente aceito para publicações de trabalhos científicos. Nas pesquisas junto às bases de dados, não se utilizou um filtro para delimitar um período de tempo para a busca de artigos, pois se entende que desta forma a pesquisa pelos trabalhos literários ocorreu de forma amplificada sem restrições.

- Passo 1.4: Um cuidado que se deve ter ao realizar uma revisão sistemática da literatura, esta relacionado a inclusão e exclusão dos trabalhos pesquisados, pois o pesquisador deve seguir um critério adequado e que não leve em consideração quaisquer juízos de valor com relação ao conteúdo dos trabalhos, mantendo critérios claros para uma seleção dos trabalhos que foram analisados. Os trabalhos analisados foram artigos de periódicos científicos. Não foram acessados trabalhos do tipo livro, imagens, teses, dissertações, monografias ou audiovisual. Foram realizados duas seleções dos trabalhos analisados. Em uma primeira seleção, adotou-se como critério a leitura de todos os resumos dos trabalhos que apareceram como resultado das buscas nas bases de dados, com base nas palavras-chave definidas no passo 1.3 da etapa de planejamento. Os critérios de inclusão dos artigos contemplavam:

i. Trabalhos que contextualizavam ou mesmo apresentavam as características das plataformas logísticas, podendo ser trabalhos voltados a estudo de casos, revisão de literatura, pesquisas de campo dentre outros tipos de pesquisas;

ii. Trabalhos que apresentassem informações relacionadas aos desafios e oportunidades da utilização das plataformas logísticas, tanto no âmbito público ou mesmo privado. Os trabalhos que não apresentam algumas destas características no seu resumo foram excluídos da fase de análise. 
A segunda etapa da revisão sistemática compreende a análise dos trabalhos que resultaram da pesquisa, conforme segue abaixo:

- Passo 2.1: Deve-se realizar uma análise profunda do conteúdo dos trabalhos selecionados no passo 1.4 da etapa 1 , considerando as obras que apresentam uma relação direta com a questão de pesquisa. Na busca de uma compreensão adequada sobre a temática investigada, foi necessária a realização de inúmeras leituras em profundidade dos trabalhos selecionados, a fim de obter uma melhor compreensão do conteúdo abordado. Durante a análise das publicações, foram identificados os principais aspectos que pudessem responder a questão de pesquisa e também foi elaborada uma classificação do conteúdo extraído dos trabalhos e que pudessem ir ao encontro da resposta ao problema de pesquisa. Nesta etapa houve a exclusão de algumas obras que em um primeiro momento haviam sido selecionadas, com base apenas no resumo do trabalho e após a leitura integral da obra entendeu-se que não atendiam aos objetivos da pesquisa.

A terceira etapa da revisão sistemática compreende a execução da pesquisa, conforme descrito:

- Passo 3.1: A realização da pesquisa através da revisão sistemática tem como uma das suas características sistematizar o conteúdo pesquisado. Como estratégia de extratificação dos conteúdos obtidos com a pesquisa, foram elaborados inicialmente sínteses dos resultados da revisão sistemática contendo a quantidade de artigos encontrados na busca na base de dados, as tipologias utilizadas nos trabalhos para denominação de plataformas logísticas e enfoque que as obras abordavam sobre o tema de pesquisa. Após esta etapa inicial, realizou-se a análise do conteúdo das publicações a fim atender aos objetivos propostos pela pesquisa.

Na seção a seguir demonstra-se os resultados da revisão sistemática realizada e as discussões sobre os achados da pesquisa. 


\section{Execução da pesquisa através da revisão sistemática}

Após a aplicação da metodologia de revisão sistemática para estruturação do trabalho, realizou-se a execução da pesquisa, que compreende a etapa 3 prevista na metodologia empregada no trabalho. Utilizando as palavras-chave selecionadas e também os critérios de pesquisa previamente definidos na etapa de planejamento, obteve-se inicialmente um total de 90 artigos publicados e localizados junto as bases de dados consultadas, conforme a Tabela 2:

Tabela 2 - Total de publicações resultantes da seleção da etapa de planejamento ${ }^{2}$

\begin{tabular}{cccccc}
\hline \multirow{2}{*}{ Base de Dados } & \multicolumn{5}{c}{ Palavras-chave } \\
\cline { 2 - 6 } & $\begin{array}{c}\text { Platforms } \\
\text { logistics }\end{array}$ & $\begin{array}{c}\text { Logistics } \\
\text { Platforms }\end{array}$ & Distripark & Distriport & $\begin{array}{c}\text { Freight } \\
\text { Village }\end{array}$ \\
\hline $\begin{array}{c}\text { Academic Search Premier - ASP } \\
\text { (EBSCO) }\end{array}$ & - & - & - & - & - \\
ACM Digital Library & - & - & - & - & - \\
ACS Journals Search & - & - & - & - & - \\
Cambridge Journals Online & - & - & - & - & - \\
Emerald Fulltext (Emerald) & - & 2 & 1 & - & - \\
IEEE Xplore & - & - & - & - & - \\
OneFile (GALE) & 6 & 13 & 9 & 4 & 3 \\
Press & - & - & - & - & - \\
Oxford Journals (Oxford University & 4 & 10 & 15 & 3 & 14 \\
ScienceDirect (Elsevier) & - & 1 & 3 & - & 2 \\
SpringerLink (MetaPress) & - & - & - & - & - \\
Wiley Online Library & 10 & 26 & 28 & 7 & 19 \\
\hline Total de Artigos & & & & & \\
\hline
\end{tabular}

Através da Com base nos resultados demonstrados na Tabela 2, constataram-se as seguintes evidências:

Base de Dados: Como resultado da pesquisa realizada para seleção dos artigos, constatou-se que 51\% dos artigos estavam na base ScienceDirect (Elsevier), 39\% na OneFile (GALE), 7\% na SpringerLink (MetaPress) e 3\% na base Emerald Fulltext (Emerald). Nas bases de dados Academic Search Premier - ASP (EBSCO), ACM Digital Library, ACS Journals Search,

${ }^{2}$ Fonte: elaborada pelos autores. 
Cambridge Journals Online, IEEE Xplore, Oxford Journals (Oxford University Press) e Wiley Online Library não foram encontrados publicações utilizando as palavras chaves propostas na etapa 1 no passo 1.3 do planejamento.

Palavras-chave: Através dos resultados obtidos, evidenciou-se que $31 \%$ dos trabalhos pesquisados utilizavam o termo Distripark, 29\% Logistics Platforms, 21\% Freight Village, $11 \%$ Platforms Logistics e $8 \%$ o termo Distriport.

Após a etapa inicial de consulta as bases de dados, realizou-se uma leitura dos resumos dos trabalhos encontrados (etapa 1 - passo 1.4) e depois uma análise profunda do conteúdo das publicações. O processo de análise é ilustrado na Figura 1:

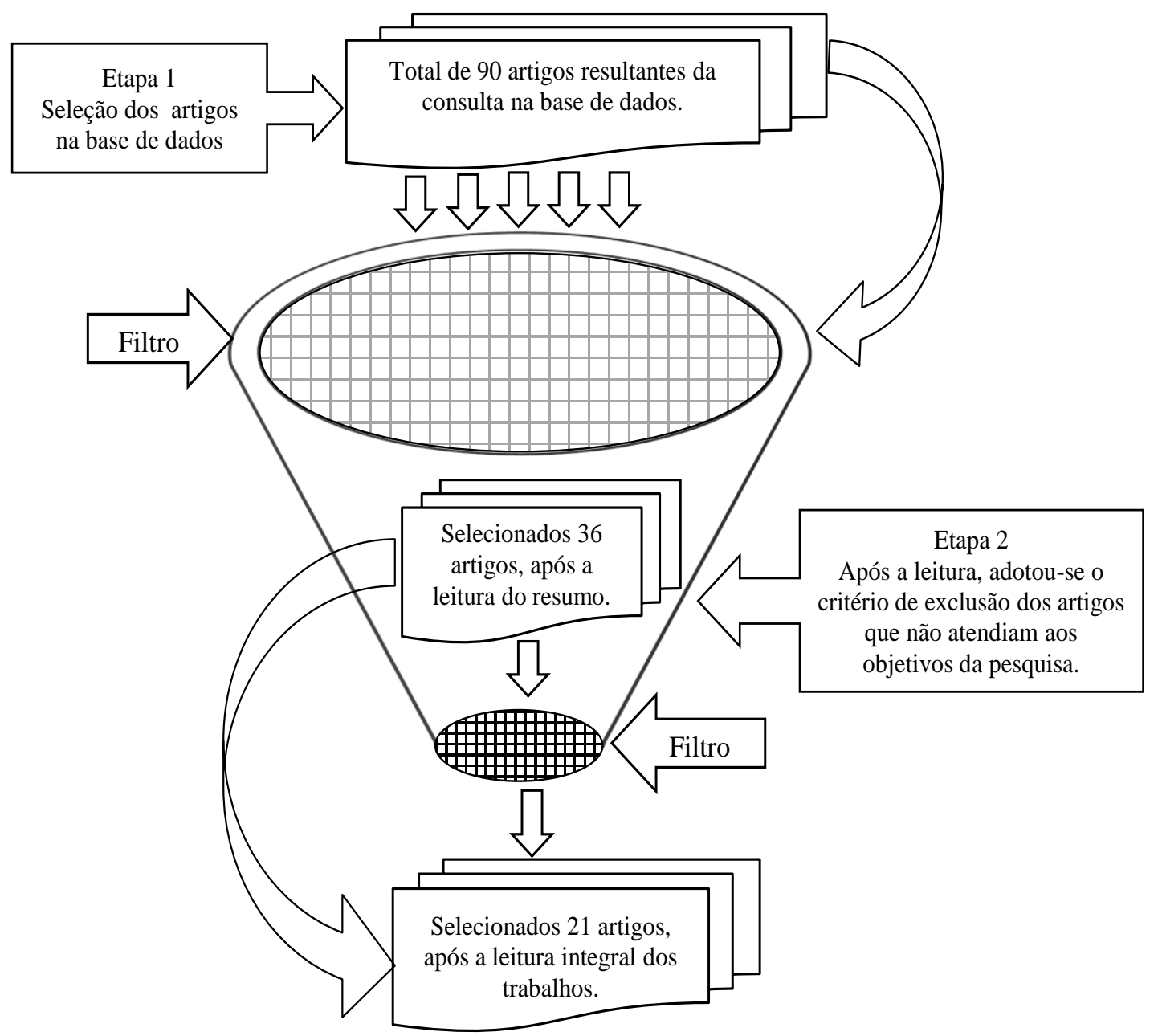

Figura 1 - Processo de seleção final dos artigos ${ }^{3}$

\footnotetext{
${ }^{3}$ A Figura 1 foi elaborada pelos autores para demonstrar o procedimento realizado no filtro dos artigos a serem analisados na revisão sistemática.
} 
Conforme pode ser observado na Figura 1, o total de artigos selecionados foi de inicialmente 90 trabalhos, sendo realizada uma leitura dos resumos chegou-se a uma seleção de 36 artigos, os quais foram submetidos a uma releitura e análise integral dos conteúdos, resultando em 21 trabalhos finais que apresentavam aderência ao tema pesquisado e respondiam a questão de pesquisa proposta neste artigo. Apresenta-se na Figura 2, a distribuição por período de tempo os trabalhos selecionados.

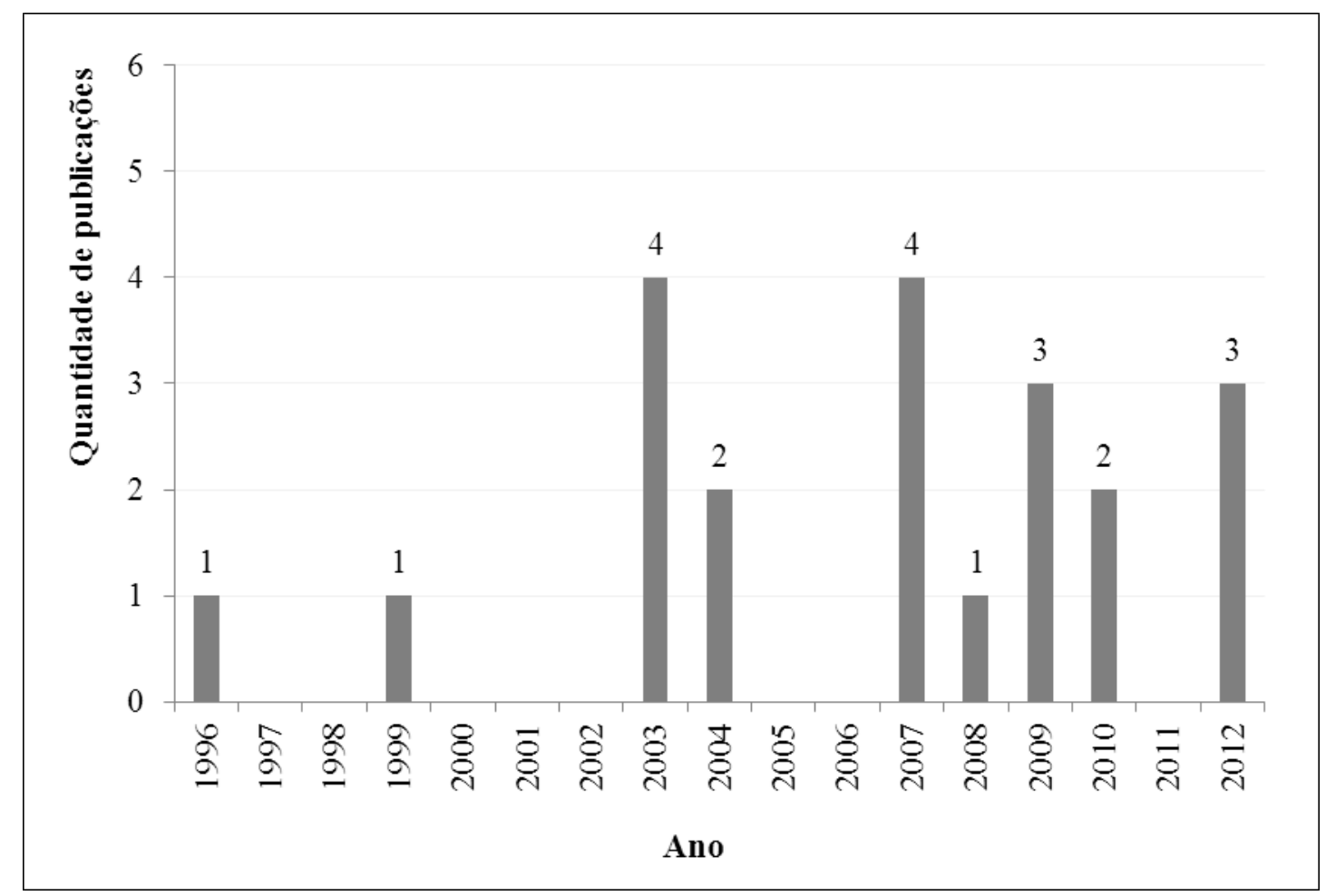

Figura 2 - Distribuição anual dos trabalhos selecionados

Em análise a Figura 2, é possível perceber uma evolução na quantidade de publicações a partir no ano de 2003 até 2012, correspondendo neste período a 90\% do total dos trabalhos selecionados. Não é possível afirmar ou mesmo ficou evidente durante a leitura dos trabalhos se houve algum tipo de causa-efeito para esta concentração no período das publicações.

Na Figura 3, apresenta-se a quantidade de artigos selecionados em relação aos periódicos em que os mesmos foram publicados. Foram selecionados 21 artigos de 18 periódicos distintos, sendo que dois periódicos apresentaram mais de 1 publicação selecionada sobre tema de pesquisa, sendo estes o Transport Policy e o Transportation. 


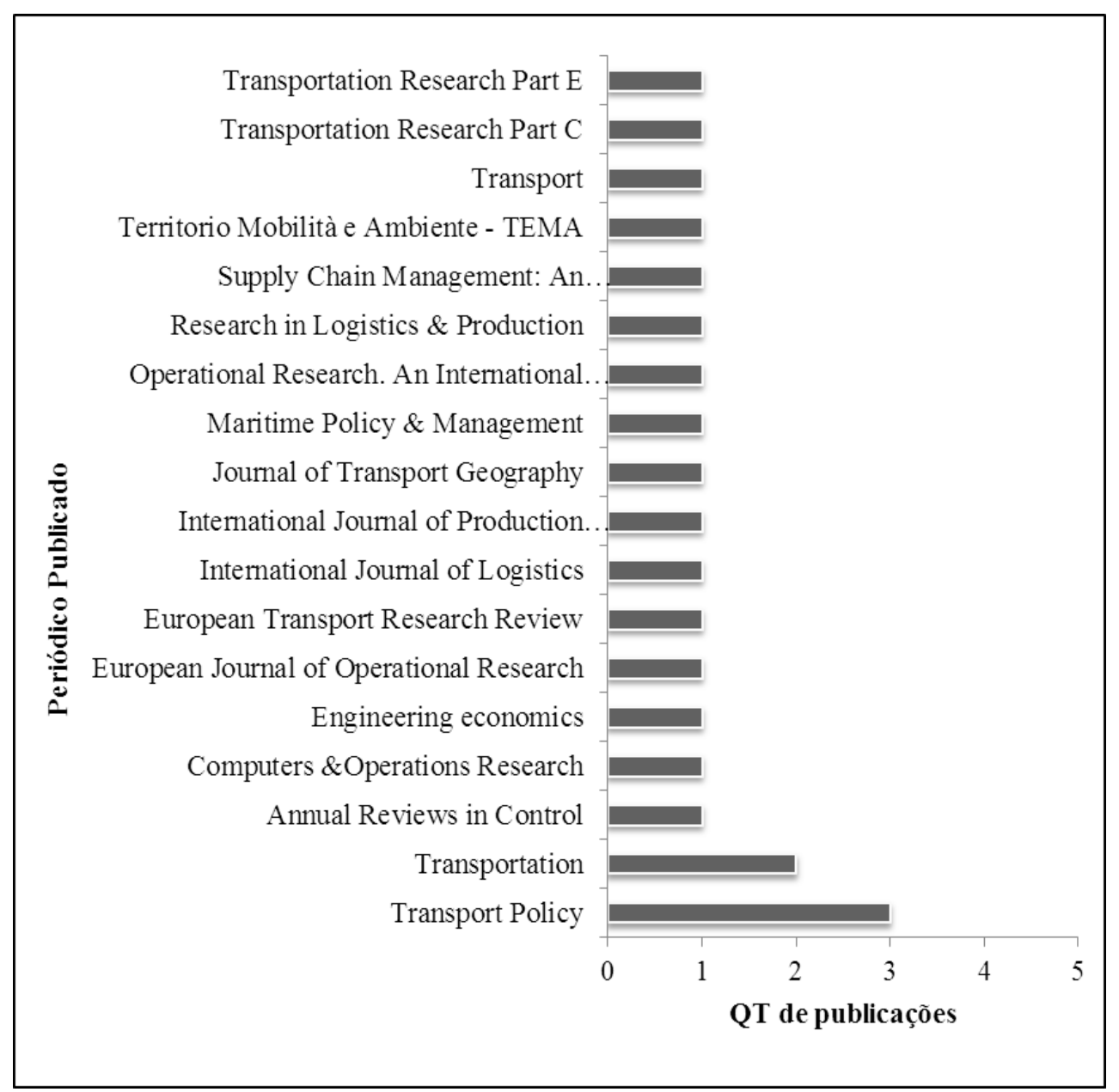

Figura 3 - Quantidade de publicações por periódico ${ }^{4}$

A partir da seleção 21 dos artigos, realizou-se uma análise dos dados encontrados com objetivo de se identificar as principais características das plataformas logísticas para a construção de um quadro conceitual deste tipo de empreendimento logístico. A síntese dos resultados é apresentada nas Tabelas 3 e 4 .

Na Tabela 3, são transcritas as informações gerais dos trabalhos selecionados onde foi verificado o método de pesquisa empregado nos trabalhos, a tipologia utilizada para denominação de plataformas logísticas e por fim o foco central do conteúdo apresentado nas publicações. Na Tabela 4, apresenta-se uma síntese das principais características das plataformas logísticas identificados pelos autores dos artigos analisados da revisão sistemática.

\footnotetext{
${ }^{4}$ Fonte: elaborada pelos autores.
} 
Tabela 3 - Classificação da estrutura dos artigos selecionados

\begin{tabular}{|c|c|c|c|c|c|}
\hline $\mathbf{N}^{\mathbf{o}}$ & Periódico & Autor (s) & $\begin{array}{l}\text { Método de } \\
\text { pesquisa }\end{array}$ & Tipologia utilizada & Foco central do conteúdo do artigo \\
\hline 1 & $\begin{array}{l}\text { International Journal of Production } \\
\text { Economics }\end{array}$ & Lu e Yang, 2007 & Quantitativo & Logistics Zones & Viabilidade Financeira/Investimentos \\
\hline 2 & Transport Policy & Konings, 1996 & Qualitativo & $\begin{array}{l}\text { Transshipment, Storage, Collection } \\
\text { and Distribution of goods (TSCD) }\end{array}$ & Localização e Estrutura \\
\hline 3 & Transport Policy & Tsamboulas e Kapros, 2003 & Quantitativo & Freight Village & Viabilidade Financeira/Investimentos \\
\hline 4 & Transport Policy & Wagner, 2010 & Quantitativo & Freight Village & Localização e Trânsito \\
\hline 6 & Computers \& OperationsResearch & Tang et al. 2012 & Quantitativo & Logistics Park & Localização e Capacidade \\
\hline 7 & European Journal of Operational Research & Aldin e Stahre, 2003 & Quantitativo & Logistics Platforms & Utilização da PL \\
\hline 8 & Journal of Transport Geography & Hesse e Rodrigue, 2004 & Quantitativo & Freight Village & Oportunidades com a PL \\
\hline 9 & Transportation Research Part E & $\mathrm{Lu}, 2003$ & Quantitativo & International Distribution Centers & Integração das operações Logísticas \\
\hline 10 & Annual Reviews in Control & Dias et al. 2009 & Qualitativo & Logistics Platforms & TI aplicado a PL \\
\hline 11 & Territorio Mobilità e Ambiente - TEMA & Campolongo et al. 2010 & Qualitativo & Logistics Platforms & Localização \\
\hline 12 & Engineering economics & Rimienė e Grundey, 2007 & Qualitativo & Logistics Centres & Abordagem teórica e conceitual \\
\hline 13 & SCM: An International Journal & Cambra-Fierro e Ruiz-Benitez, 2009 & Qualitativo & Logistics Platforms & Utilização da PL \\
\hline 14 & European Transport Research Review & Mazzarino, 2012 & Quali-Quanti & Logistics Platforms & Utilização da PL \\
\hline 15 & Transportation & Marcucci e Danielis, 2008 & Quantitativo & Freight Consolidation Centre & Utilização da PL \\
\hline 16 & $\begin{array}{c}\text { Operational Research. An International } \\
\text { Journal. }\end{array}$ & Ballis e Mavrotas, 2007 & Quantitativo & Freight Village & Localização \\
\hline 17 & Research in Logistics \& Production & Gajsek et al. 2012 & Qualitativo & Logistics Platforms & Utilização da PL \\
\hline 18 & Maritime Policy \& Management & Pettit e Beresford, 2009 & Qualitativo & Distriparks & Utilização da PL \\
\hline 19 & Transport & Meidutè, 2007 & Quantitativo & Logistics Centres & Viabilidade Financeira/ Investimentos \\
\hline 20 & Transportation & Tsamboulas e Dimitropoulos, 1999 & Quali-Quanti & Nodal Centres for Goods & Viabilidade Financeira/ Investimentos \\
\hline 21 & International journal of logistics & Abrahamsson et al. 2003 & Qualitativo & Logistics Platforms & Utilização da PL \\
\hline
\end{tabular}


Tabela 4 - Síntese das principais características dos empreendimentos (PL) destacados pelos autores

\begin{tabular}{|c|c|c|c|c|c|c|c|c|c|c|c|c|c|c|c|c|c|c|c|c|c|c|c|c|c|c|c|c|c|c|c|c|c|c|c|}
\hline \multirow[b]{2}{*}{$\mathbf{N}^{\mathbf{o}}$} & \multirow[b]{2}{*}{ Autor(s) } & \multicolumn{6}{|c|}{ Localização } & \multicolumn{5}{|c|}{ Infraestrutura } & \multicolumn{10}{|c|}{ Serviços e Atividades } & \multicolumn{7}{|c|}{ Benefícios } & \multicolumn{3}{|c|}{ Gestão } & \multicolumn{3}{|c|}{ Participantes } \\
\hline & & 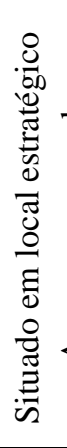 & 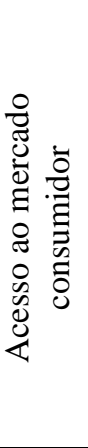 & 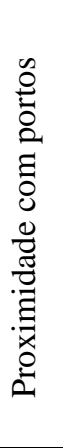 & 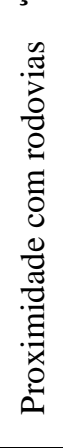 & 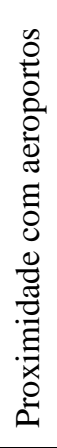 & 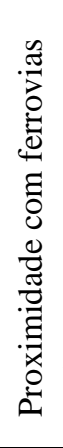 & 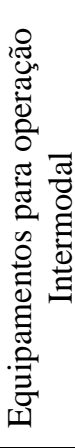 & 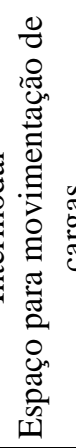 & 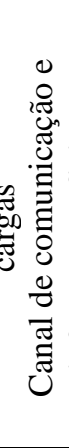 & 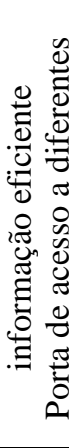 & & 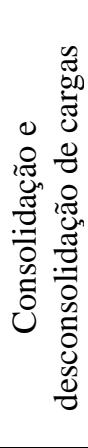 & 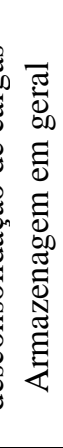 & 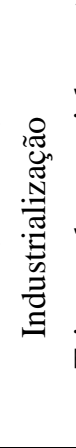 & 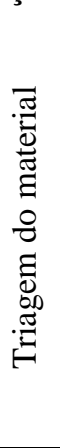 & 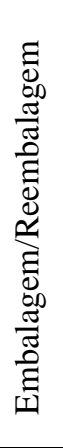 & 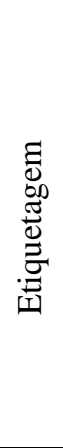 & 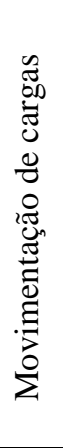 & 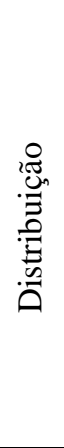 & 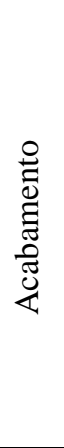 & 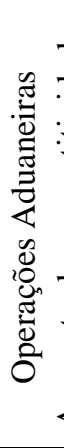 & 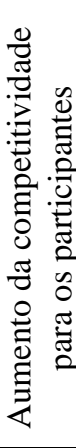 & 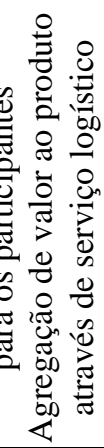 & 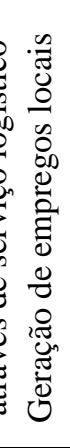 & 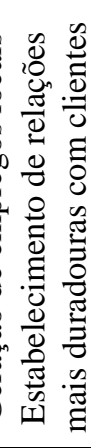 & 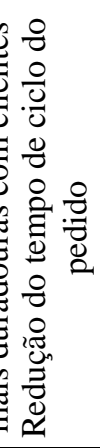 & 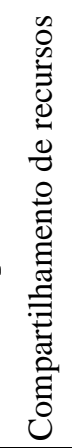 & 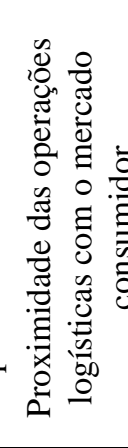 & 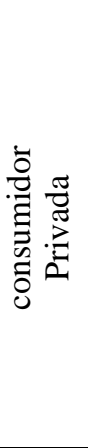 & : & 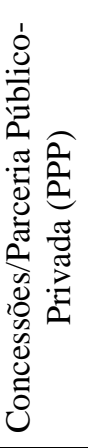 & 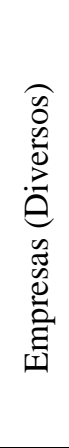 & 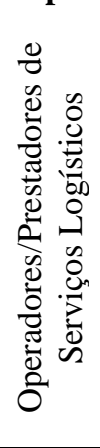 & $\begin{array}{l} \\
0 \\
0 \\
.0 \\
0 \\
0 \\
0 \\
0 \\
0 \\
00 \\
0 \\
0\end{array}$ \\
\hline 1 & Lu e Yang, 2007 & $\mathrm{X}$ & & $\mathrm{X}$ & $\mathrm{X}$ & & & $\mathrm{X}$ & $\mathrm{X}$ & & & $\mathrm{X}$ & $\mathrm{X}$ & $\mathrm{X}$ & $\mathrm{X}$ & & $\mathrm{X}$ & $\mathrm{X}$ & & $\mathrm{X}$ & & $\mathrm{X}$ & $\mathrm{X}$ & & $\mathrm{X}$ & $\mathrm{X}$ & $\mathrm{X}$ & & & $\mathrm{X}$ & $\mathrm{X}$ & & $\mathrm{X}$ & $\mathrm{X}$ & $\mathrm{X}$ \\
\hline 2 & Konings, 1996 & & $X$ & $\mathrm{X}$ & $\mathrm{X}$ & & & $X$ & $\mathrm{X}$ & $\mathrm{X}$ & & $X$ & $\mathrm{X}$ & & & & & & $X$ & $\mathrm{X}$ & & & $X$ & $\mathrm{X}$ & & & $X$ & & $\mathrm{X}$ & $\mathrm{X}$ & & & $\mathrm{X}$ & $\mathrm{X}$ & \\
\hline 3 & Tsamboulas e Kapros, 2003 & & $\mathrm{X}$ & $\mathrm{X}$ & $\mathrm{X}$ & & & $\mathrm{X}$ & $\mathrm{X}$ & & & $\mathrm{X}$ & $\mathrm{X}$ & & & & & & & $\mathrm{X}$ & & & $\mathrm{X}$ & & & & $\mathrm{X}$ & & $\mathrm{X}$ & & & $\mathrm{X}$ & $\mathrm{X}$ & $X$ & $\mathrm{X}$ \\
\hline 4 & Wagner, 2010 & $X$ & $X$ & & & & & $\mathrm{X}$ & $\mathrm{X}$ & $\mathrm{X}$ & & $X$ & $\mathrm{X}$ & & & & & & $\mathrm{X}$ & $\mathrm{X}$ & & & & $\mathrm{X}$ & & & $\mathrm{X}$ & & $\mathrm{X}$ & $X$ & & & $X$ & $X$ & \\
\hline 5 & Crainic et al. 2004 & $X$ & $\mathrm{X}$ & $\mathrm{X}$ & $\mathrm{X}$ & $\mathrm{X}$ & $\mathrm{X}$ & & $\mathrm{X}$ & $\mathrm{X}$ & & $X$ & $\mathrm{X}$ & $\mathrm{X}$ & & $\mathrm{X}$ & & & $\mathrm{X}$ & $\mathrm{X}$ & & & $\mathrm{X}$ & $\mathrm{X}$ & & $X$ & $\mathrm{X}$ & $X$ & $X$ & $X$ & $\mathrm{X}$ & $X$ & $\mathrm{X}$ & $\mathrm{X}$ & $\mathrm{X}$ \\
\hline 6 & Tang et al. 2012 & $\mathrm{X}$ & $X$ & & & & & & $\mathrm{X}$ & & & $\mathrm{X}$ & $\mathrm{X}$ & $\mathrm{X}$ & & & & & $\mathrm{X}$ & $\mathrm{X}$ & & & & $X$ & & & $\mathrm{X}$ & $\mathrm{X}$ & $\mathrm{X}$ & $\mathrm{X}$ & $\mathrm{X}$ & & $\mathrm{X}$ & $X$ & \\
\hline 7 & Aldin e Stahre, 2003 & $\mathrm{X}$ & $\mathrm{X}$ & & & & & $\mathrm{X}$ & $\mathrm{X}$ & $\mathrm{X}$ & & $X$ & $\mathrm{X}$ & $\mathrm{X}$ & $\mathrm{X}$ & & $\mathrm{X}$ & $\mathrm{X}$ & $\mathrm{X}$ & $\mathrm{X}$ & & & $X$ & $\mathrm{X}$ & & $\mathrm{X}$ & $\mathrm{X}$ & $\mathrm{X}$ & $\mathrm{X}$ & $\mathrm{X}$ & & & $\mathrm{X}$ & $\mathrm{X}$ & \\
\hline 8 & Hesse e Rodrigue, 2004 & $\mathrm{X}$ & & & & & & & & $\mathrm{X}$ & & $\mathrm{X}$ & $\mathrm{X}$ & $\mathrm{X}$ & & & & & $\mathrm{X}$ & $\mathrm{X}$ & & & $X$ & $\mathrm{X}$ & & $\mathrm{X}$ & $X$ & $\mathrm{X}$ & $X$ & $\mathrm{X}$ & & & $\mathrm{X}$ & $X$ & \\
\hline 9 & Lu, 2003 & $\mathrm{X}$ & & $X$ & $\mathrm{X}$ & $\mathrm{X}$ & $\mathrm{X}$ & $X$ & $\mathrm{X}$ & $\mathrm{X}$ & & $\mathrm{X}$ & $\mathrm{X}$ & $X$ & & & & & $\mathrm{X}$ & $\mathrm{X}$ & & $\mathrm{X}$ & $X$ & $X$ & & & $\mathrm{X}$ & $\mathrm{X}$ & & $\mathrm{X}$ & $X$ & & $\mathrm{X}$ & $\mathrm{X}$ & $\mathrm{X}$ \\
\hline 10 & Dias et al. 2009 & $\mathrm{X}$ & & $X$ & $\mathrm{X}$ & $\mathrm{X}$ & $\mathrm{X}$ & $\mathrm{X}$ & $\mathrm{X}$ & $\mathrm{X}$ & & & $X$ & $\mathrm{X}$ & $\mathrm{X}$ & & $\mathrm{X}$ & & $\mathrm{X}$ & $\mathrm{X}$ & $X$ & & $X$ & $X$ & & & $\mathrm{X}$ & $\mathrm{X}$ & $X$ & $\mathrm{X}$ & & & & & \\
\hline 11 & Campolongo et al. 2010 & $\mathrm{X}$ & & $\mathrm{X}$ & $\mathrm{X}$ & & & & $\mathrm{X}$ & $\mathrm{X}$ & & $\mathrm{X}$ & $\mathrm{X}$ & $\mathrm{X}$ & & & & & $\mathrm{X}$ & $\mathrm{X}$ & & & & $\mathrm{X}$ & $X$ & & & & $X$ & $\mathrm{X}$ & $\mathrm{X}$ & & $\mathrm{X}$ & $X$ & $\mathrm{X}$ \\
\hline 12 & Rimienè e Grundey, 2007 & $\mathrm{X}$ & $X$ & & & & & $\mathrm{X}$ & $\mathrm{X}$ & $X$ & & $\mathrm{X}$ & $\mathrm{X}$ & $\mathrm{X}$ & & $\mathrm{X}$ & $\mathrm{X}$ & $X$ & $X$ & $X$ & & $\mathrm{X}$ & $\mathrm{X}$ & $X$ & & $\mathrm{X}$ & $\mathrm{X}$ & $\mathrm{X}$ & $\mathrm{X}$ & $\mathrm{X}$ & & & $\mathrm{X}$ & $X$ & $\mathrm{X}$ \\
\hline 13 & $\begin{array}{l}\text { Cambra-Fierro e Ruiz-Benitez, } \\
2009\end{array}$ & $\mathrm{X}$ & & $\mathrm{X}$ & $\mathrm{X}$ & $\mathrm{X}$ & $\mathrm{X}$ & $\mathrm{X}$ & $\mathrm{X}$ & $\mathrm{X}$ & & & $\mathrm{X}$ & $\mathrm{X}$ & & & & & $\mathrm{X}$ & $\mathrm{X}$ & & & $\mathrm{X}$ & $\mathrm{X}$ & & $X$ & $\mathrm{X}$ & $\mathrm{X}$ & $\mathrm{X}$ & $X$ & $\mathrm{X}$ & & $X$ & $X$ & $\mathrm{X}$ \\
\hline 14 & Mazzarino, 2012 & $\mathrm{X}$ & & & & & & & & $\mathrm{X}$ & & $\mathrm{X}$ & $\mathrm{X}$ & $\mathrm{X}$ & $\mathrm{X}$ & & & & $\mathrm{X}$ & $\mathrm{X}$ & & & $\mathrm{X}$ & $\mathrm{X}$ & & & $\mathrm{X}$ & $\mathrm{X}$ & $\mathrm{X}$ & $\mathrm{X}$ & & & $\mathrm{X}$ & $\mathrm{X}$ & \\
\hline 15 & Marcucci e Danielis, 2008 & $\mathrm{X}$ & $X$ & & & & & & & $\mathrm{X}$ & & & $\mathrm{X}$ & $X$ & & & & & $X$ & $\mathrm{X}$ & & & $X$ & $X$ & & & $\mathrm{X}$ & $\mathrm{X}$ & & $\mathrm{X}$ & & & $\mathrm{X}$ & $X$ & \\
\hline 16 & Ballis e Mavrotas, 2007 & $\mathrm{X}$ & $X$ & & & & & $X$ & $\mathrm{X}$ & $\mathrm{X}$ & & & $\mathrm{X}$ & $\mathrm{X}$ & & & $\mathrm{X}$ & $\mathrm{X}$ & $\mathrm{X}$ & $\mathrm{X}$ & & & $X$ & $X$ & $\mathrm{X}$ & & $X$ & $\mathrm{X}$ & $X$ & $\mathrm{X}$ & $\mathrm{X}$ & & $\mathrm{X}$ & $X$ & $\mathrm{X}$ \\
\hline 17 & Gajšek et al. 2012 & $\mathrm{X}$ & $\mathrm{X}$ & & $\mathrm{X}$ & $\mathrm{X}$ & & & $\mathrm{X}$ & & & & $X$ & $X$ & & & & & $X$ & $\mathrm{X}$ & & & $X$ & $X$ & & & $\mathrm{X}$ & $\mathrm{X}$ & $\mathrm{X}$ & $X$ & $X$ & & $\mathrm{X}$ & $\mathrm{X}$ & $\mathrm{X}$ \\
\hline 18 & Pettit e Beresford, 2009 & $\mathrm{X}$ & $X$ & $X$ & & & & $\mathrm{X}$ & $\mathrm{X}$ & $\mathrm{X}$ & & & $\mathrm{X}$ & $\mathrm{X}$ & & & & & $\mathrm{X}$ & $\mathrm{X}$ & & $\mathrm{X}$ & $X$ & $\mathrm{X}$ & & & $\mathrm{X}$ & $\mathrm{X}$ & $\mathrm{X}$ & $X$ & $\mathrm{X}$ & & $\mathrm{X}$ & $\mathrm{X}$ & $\mathrm{X}$ \\
\hline 19 & Meidute, 2007 & $\mathrm{X}$ & $\mathrm{X}$ & $\mathrm{X}$ & $\mathrm{X}$ & $\mathrm{X}$ & $\mathrm{X}$ & $\mathrm{X}$ & $\mathrm{X}$ & $\mathrm{X}$ & & & $\mathrm{X}$ & $\mathrm{X}$ & & & $\mathrm{X}$ & & $\mathrm{X}$ & $\mathrm{X}$ & & & $\mathrm{X}$ & $\mathrm{X}$ & & & $X$ & $\mathrm{X}$ & $\mathrm{X}$ & $\mathrm{X}$ & $\mathrm{X}$ & $\mathrm{X}$ & $\mathrm{X}$ & $\mathrm{X}$ & $\mathrm{X}$ \\
\hline 20 & $\begin{array}{c}\text { Tsamboulas e Dimitropoulos, } \\
1999\end{array}$ & $\mathrm{X}$ & $\mathrm{X}$ & $\mathrm{X}$ & $\mathrm{X}$ & & & $\mathrm{X}$ & $\mathrm{X}$ & & & $\mathrm{X}$ & $\mathrm{X}$ & $X$ & & & & & $\mathrm{X}$ & $\mathrm{X}$ & & $\mathrm{X}$ & $\mathrm{X}$ & $\mathrm{X}$ & $\mathrm{X}$ & & $\mathrm{X}$ & & $\mathrm{X}$ & $\mathrm{X}$ & $\mathrm{X}$ & & $\mathrm{X}$ & $\mathrm{X}$ & $\mathrm{X}$ \\
\hline 21 & Abrahamsson et al. 2003 & $\mathrm{X}$ & & & & & & $\mathrm{X}$ & $\mathrm{X}$ & $\mathrm{X}$ & & $X$ & $\mathrm{X}$ & $\mathrm{X}$ & $\mathrm{X}$ & & $\mathrm{X}$ & $\mathrm{X}$ & $\mathrm{X}$ & $\mathrm{X}$ & & & $\mathrm{X}$ & $\mathrm{X}$ & & $X$ & $\mathrm{X}$ & $\mathrm{X}$ & $\mathrm{X}$ & $\mathrm{X}$ & & & $\mathrm{X}$ & $\mathrm{X}$ & \\
\hline
\end{tabular}




\section{Análise e Discussões dos resultados da Revisão Sistemática}

Com relação ao método empregado nos trabalhos pesquisados, constata-se que $52 \%$ tem uma abordagem quantitativa, 38\% qualitativa e 10\% quali-quanti, conforme a Figura 4.

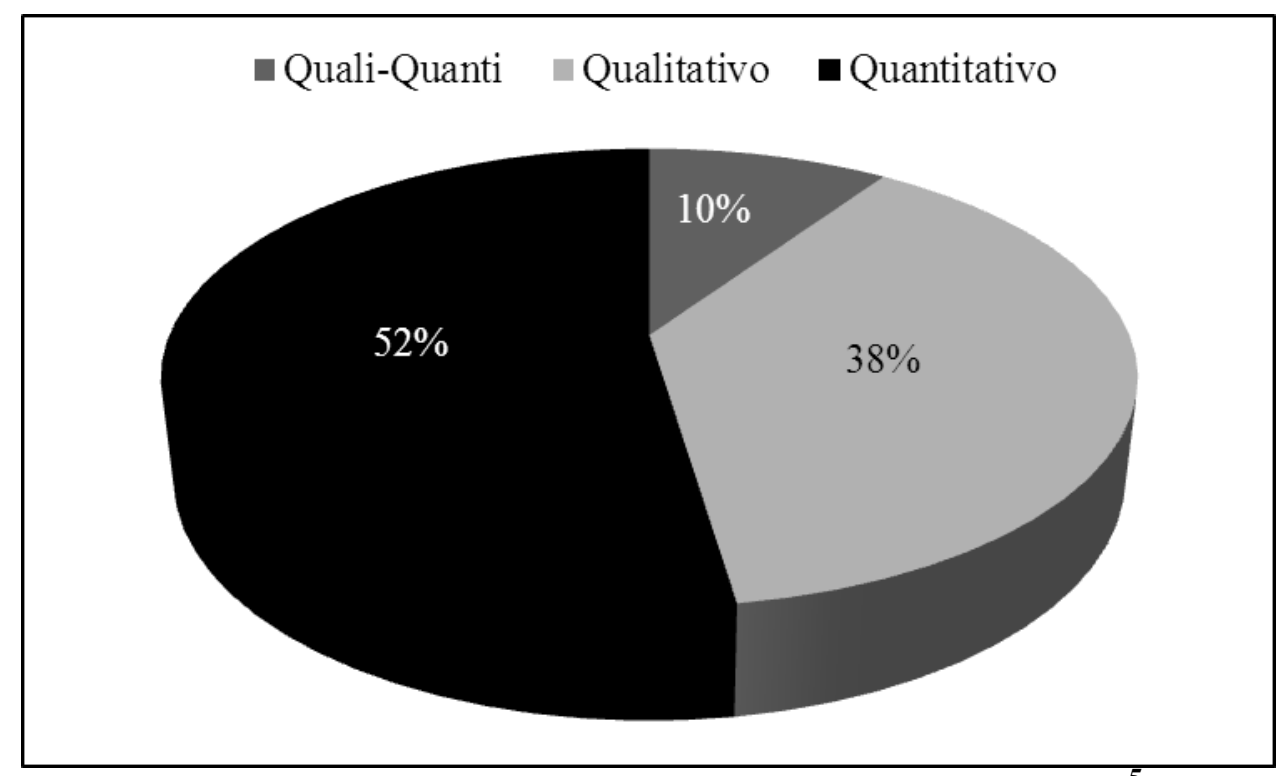

Figura 4 - Método de pesquisa dos artigos selecionados ${ }^{5}$

Percebe-se diferentes tipologias e características dos empreendimentos logísticos denominados plataformas logísticas, os quais podem ser classificados, em razão das especificidades das operações realizadas, local de funcionamento e fundamentos teóricos e concepções. Segue abaixo as tipologias e características das plataformas logísticas resultantes dos trabalhos analisados:

- Distriparks: são parques logísticos providos de facilidades em uma área concentrada sendo administrados ou não por operadores logísticos internacionais em áreas próximas a portos de grande movimentação (Pettit e Beresford, 2009);

- Freight Consolidation Centre: refere-se a uma área logística localizada perto dos centros das cidades, onde possam ser realizadas consolidações de entregas assim como oferecer outros serviços logísticos de valor agregado ao varejo (Marcucci e Danielis, 2008);

\footnotetext{
${ }^{5}$ Fonte: elaborada pelos autores.
} 
- Freight Village: são áreas logísticas, geralmente localizadas em uma região mais afastada dos grandes centros. Estes novos espaços, devem ser planejados de forma conjunta ao planejamento urbano das cidades, pois deve-se avaliar os impactos que podem ser gerados em razão da instalação deste novos empreendimentos como os ambientais, tráfego de veículos dentre outros aspectos. As plataformas logísticas envolvem alianças entre entidades responsáveis pelo transporte, serviços de armazenagem e distribuição que podem gerar significativas reduções no tráfego urbano, na poluição ambiental e também minimizar os prejuízos no âmbito social. A plataforma logística é uma estrutura que se destina a responder às necessidades específicas da gestão dos fluxos físicos e informações de produtos, que são projetados para garantir condições adequadas para a mobilidade do mercado de bens: da produção à distribuição (Tsamboulas et al. 2003; Wagner, 2010; Hesse e Rodrigue, 2004; Ballis e Mavrotas, 2007);

- International Distribution Centers: é definido como um lugar que integra as operações de fabricação com o transporte, armazenamento, portos e operações aduaneiras a fim de obter uma distribuição eficiente de mercadorias (Lu, 2003);

- Logístics Zones: uma zona de logística é um local que dispõe as empresas um lugar para armazenar ou manter suas matérias-primas, produtos semiacabados ou acabados por um determinado período de tempo (Lu e Yang, 2007);

- Logistics Centres ou Centro de Logística: é um local do sistema logístico, incluindo as instalações logísticas, onde os operadores realizam diversos serviços ligados ao transporte, logística e distribuição na cobertura geográfica estabelecida. Um Centro de Logística pode ser considerado como um centro de mercadorias e ou um centro de distribuição (Rimienè e Grundey, 2007; Meidutè, 2007);

- Logistics Park: o parque logístico é projetado para cooperar com centros de logística, diminuir a demanda de abastecimento de estoque e adequar os custos com transportes para as empresas (Tang et al. 2012);

- Logistics Platforms: deve ser um ambiente flexível capaz de responder as estratégias dos canais do mercado. Neste ambiente são realizadas atividades 
logísticas (armazenagem, transbordo de cargas, cross-docking dentre outros) e os processos devem ser padronizados e medidos. A utilização de uma plataforma logística pode servir como uma fonte de vantagem competitiva, integrando atividades dentro de um cenário específico da cadeia de suprimentos sendo visto como um fator determinante e de sucesso para muitas empresas. Uma das características e pré-requisitos principais do conceito de plataforma logística esta relacionado aos seus objetivos, os quais devem ser estabelecidos pelos seus participantes. A plataforma logística inclui conceitos de operações integradas de logística no âmbito de estrutura física, processos e suas atividades, bem como os sistemas de informação necessários ao desenvolvimento das operações e geração de relatórios (Aldin e Stahre, 2003; Dias et al. 2009; Campolongo et al. 2010; Cambra-Fierro e Ruiz-Benitez, 2009; Mazzarino, 2012; Gajšek et al. 2012; Abrahamsson, 2003; Crainic et al. 2004);

- Nodal Centres for Goods: é uma plataforma integradora de vários modos de transporte, capaz de promover o transporte intermodal entre múltiplas origens e destinos. É constituída por vários nós os quais as mercadorias sofrem o transbordo da carga de um modal de transporte para outro (Tsamboulas e Dimitropoulos, 1999);

- Transshipment, Storage, Collection and Distribution of goods (TSCD): são classificados como um centro integrado e caracterizados pelo espaço e funções de integração das operações e estocagem, como um negócio adicional intensificando o transporte (Konings, 1996).

Nas publicações consultadas, verificou-se que a tipologia utilizada pelos diferentes autores para caracterizar os empreendimentos logísticos denominados plataformas logísticas, pode ser distinta não havendo uma definição única. Na Figura 5, demonstram-se os resultados quantitativos relativos a tipologia apresentadas nos artigos: 


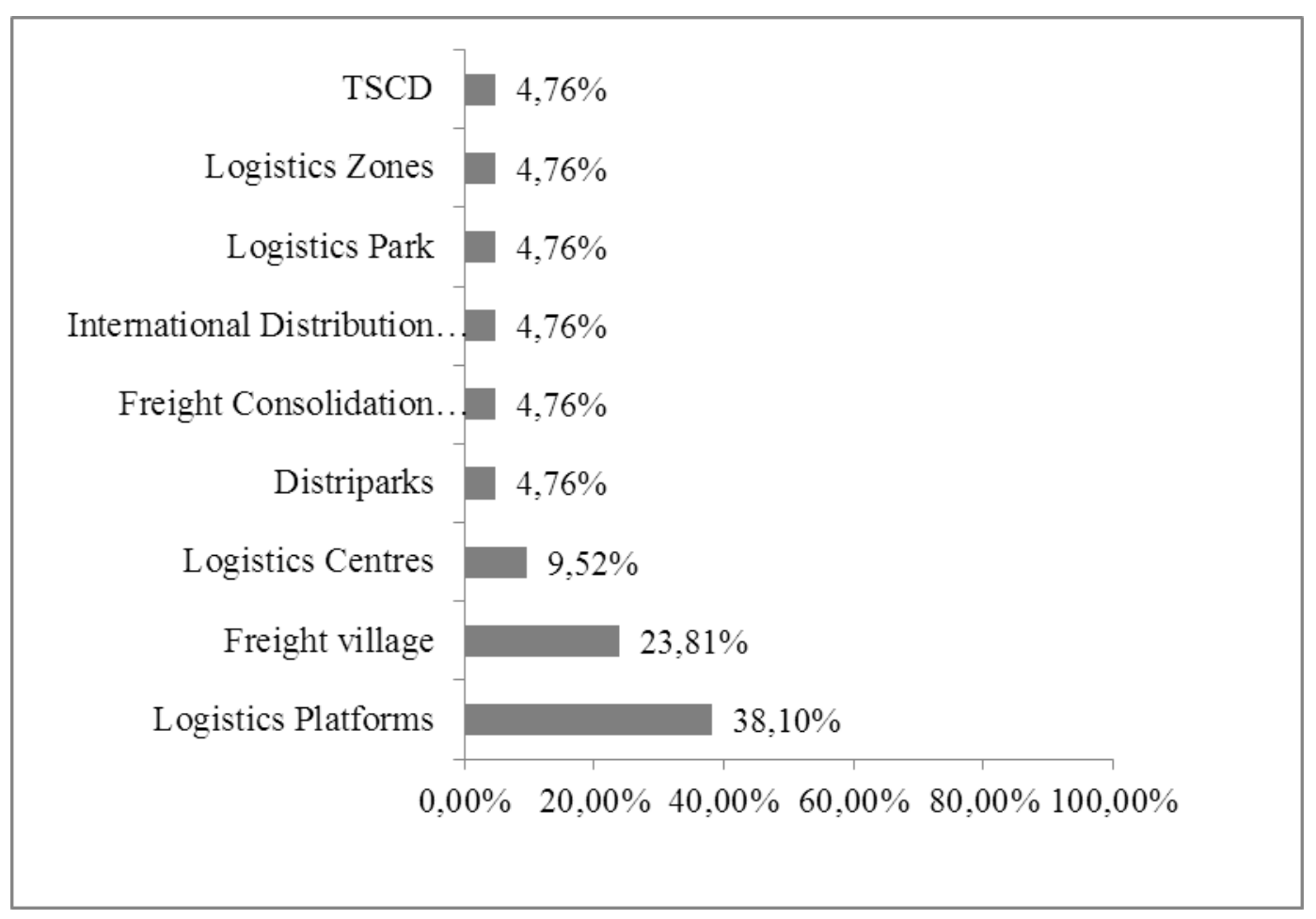

Figura 5 - Tipologia de PL's utilizadas nos artigos selecionados 6

Independentemente das diversas tipologias utilizadas pelos autores para concepção dos empreendimentos logísticos com características de plataformas logísticas, constata-se que as plataformas logísticas (PL’s) são geralmente empreendimentos de grande porte, os quais necessitam de áreas amplas e que sejam capazes de absorver as diversas operações logísticas realizadas em um mesmo ambiente.

Os locais dispõe de instalações físicas como armazéns, áreas de administração, áreas de conveniência dentre outras. Alguns fatores como o acesso ao diferentes modais de transporte, infraestrutura de rodovias, pontos de acesso aos principais mercados atendidos pelo empreendimento logístico, disponibilidade de serviços e mão de obra devem ser considerados no momento da decisão pela localização das PL's.

Para Regan e Golob (2005), o alto custo da terra pode inviabilizar a instalação das plataformas próxima aos centros urbanos, sendo necessária uma infraestrutura ágil de acesso ao mercado consumidor. O projeto de instalações das plataformas logísticas deve levar em consideração o planejamento urbano do local, pois é necessário avaliar os impactos que podem ser gerados pela instalação por este tipo de empreendimentos como: impactos ambientais, aumento do tráfego de veículos, fluxo de pessoas dentre

\footnotetext{
${ }^{6}$ Fonte: elaborada pelos autores.
} 
outros aspectos (Wagner, 2010). A localização das PL's deve ser estratégica, pois se busca uma sinergia entre os diferentes recursos envolvidos sob forma de potencializar os ganhos a serem obtidos. $\mathrm{O}$ acesso rápido ao mercado consumidor e a multimodalidade das plataformas logísticas são variáveis relevantes na escolha da localização. Entre os modais utilizados, a proximidade com a zona portuária aparece em destaque entre os trabalhos consultados.

Com relação a infraestrutura das plataformas logísticas PL, deve se levar em consideração aspectos operacionais de funcionamento das plataformas e também os serviços e instalações disponíveis aos usuários. Os equipamentos para movimentação das cargas devem ser compatíveis com as atividades realizadas. Dias et al. (2009), destaca que em razão da complexidade das atividades logísticas desempenhadas e também da própria manutenção do nível de serviço logístico, é necessário que se tenha um canal de comunicação eficiente através do uso da tecnologia de informações.

As atividades logísticas e os serviços logísticos desenvolvidos em uma plataforma logística, são os mais diversos, podem variar desde a armazenagem, movimentação da carga, consolidação e ou desconsolidação chegando até a realização da industrialização dos produtos. Entre as atividades e serviços realizados, as atividades de consolidação e desconsolidação de cargas, movimentação de mercadorias e a distribuição apresentam uma maior representatividade nestes ambientes (Tsamboulas e Kapros, 2003; Dias et al. 2009). As plataformas logísticas instaladas em locais que tenham acessibilidade a diferentes tipos de modais apresentam geralmente um maior número de atividades e serviços logísticos realizados.

Os benefícios gerados pela utilização de plataformas logísticas estão relacionados a possibilidade de realização de diversas atividades de valor agregado e de forma integrada ao sistema logístico, como embalagem, consolidação, rotulagem, movimentação de carga dentre outros promovendo uma sinergia entre os processos logísticos. Com relação ao compartilhamento dos recursos e infraestrutura, como instalações e equipamentos podem possibilitar a redução dos custos (Lu e Yang, 2007). A utilização racional dos recursos de forma conjunta em um mesmo ambiente pode levar a uma redução do tempo do ciclo do pedido para os clientes. De forma geral a utilização de plataformas logísticas, podem servir como uma forma de obter a vantagem competitiva, integrando atividades dentro de um cenário específico da cadeia de 
suprimentos sendo visto como um fator determinante e de sucesso para muitas organizações (Cambra-Fierro e Ruiz-Benitez, 2009).

A gestão das plataformas logísticas pode ser privada, pública ou mesmo um misto entre as duas formas. Geralmente a gestão dos empreendimentos é centralizada, onde se tem a responsabilidade pelo planejamento das operações, o controle dos investimentos a serem realizados e também a administração e o suporte para o funcionamento local. A governança deve incluir controles rígidos, sejam estes relacionados a qualidade, segurança, riscos, gestão ambiental dentre outros aspectos. Os investimentos realizados em plataformas logísticas podem ser considerados elevados e muitas vezes realizados sobre o conceito de uma parceria público-privada, sendo necessário o cumprimento de contratos e também uma adequada mensuração do desempenho do empreendimento. Um dos pontos críticos a serem considerados pela gestão nas plataformas relaciona-se aos objetivos singulares dos atores envolvidos nos processos logísticos.

As plataformas logísticas são ambientes complexos, os quais demandam a compreensão adequada das principais atividades realizadas, os atores envolvidos e principalmente os objetivos propostos com a utilização deste tipo de empreendimento logístico. As plataformas logísticas mostram-se como uma realidade em países desenvolvidos, tendo um papel ativo na logística das organizações e no âmbito público possibilitam uma reorganização dos espaços urbanos e também contribuem para uma melhor gestão e racionalização das questões ambientais, sociais, políticas e econômicas.

As cadeias de abastecimento estão se tornando cada vez mais globalizadas, levando a uma mudança e utilização intensiva de uma logística mais eficiente. As tendências de consumo e produção alteram de forma substancial os padrões de distribuição, contribuindo para um redesenho dos arranjos logísticos com objetivo de tornar os mesmos mais flexíveis e capazes de responder rapidamente as demandas do mercado consumidor.

De acordo com Porter (2000), o arranjo de organizações sejam estas empresas de prestação de serviços ou indústrias em um mesmo ambiente auxiliam a conseguir um produto ou mesmo um serviço com uma maior qualidade e eficiência, pois acabam desenvolvendo sinergias entre si e cooperando para poder competir. A criação de centros de logística possibilita uma sinergia entre as organizações participantes gerando 
benefícios que vão desde a utilização compartilhada de uma infraestrutura logística, podendo aumentar a produtividade e reduzir o ciclo do pedido do cliente, inovação nos serviços prestados e agregação de valor ao produto final (Notteboom e Rodrigue, 2005; Mccalla et al. 2001).

\section{Conclusão}

Os resultados obtidos através da revisão sistemática possibilitaram aos pesquisadores uma visibilidade sobre as diferentes tipologias utilizadas e características dos empreendimentos logísticos do tipo plataformas logísticas. Ainda neste contexto, constata-se os desafios e oportunidades de utilização das plataformas no âmbito privado e público.

Com relação aos desafios logísticos contemporâneos sobrepostos as organizações privadas ou mesmo entidades públicas, percebe-se a oportunidade de utilização das plataformas logísticas e discutem-se os seguintes aspectos:

- No âmbito da logística empresarial, as organizações são confrontadas a adaptarse de forma rápida as mudanças, sejam estas relacionadas aos seus canais de fornecimento ou mesmo as suas redes de distribuição o que acaba impactando na estrutura e estratégia logística disponível pelas empresas que estão inseridas neste contexto. A busca por uma redução dos níveis de estoques ao longo da cadeia de suprimentos, uma redução do tempo do ciclo do pedido ao cliente, a adequação dos custos dentre outros fatores tem feito com que muitas organizações busquem alternativas para obter uma maior eficiência em seus negócios, e neste sentido a utilização de plataformas logísticas, mostra-se como um caminho ou mesmo uma alternativa para o desenvolvimento de soluções conjuntas e agregadoras através da otimização dos recursos (transportes, espaços físicos, movimentação de materiais dentre outros) aspectos envolvidos na logística de suprimentos, produção ou distribuição dos produtos. Entende-se que a aglomeração dos diversos atores em um mesmo ambiente evidência a necessidade de um adequado alinhamento dos objetivos entre os envolvidos, e por conta disto se faz necessário estabelecer critérios claros para a gestão e governança das plataformas logísticas; 
- Na esfera pública o transporte urbano de mercadorias enfrenta atualmente desafios claros os quais estão relacionados ao crescimento da população nos centros urbanos, a ocupação de forma desordenada de algumas áreas, os congestionamentos, a poluição gerada pelos veículos e principalmente a circulação de pessoas e veículos de cargas em um mesmo tempo e ambiente dentre outros aspectos. Estas situações vêm impondo aos governantes a busca de soluções mais robustas e que possam atender aos diferentes interesses dos agentes envolvidos neste contexto. As plataformas logísticas podem contribuir para uma maior eficiência na logística de distribuição e também gerar outros benefícios de forma indireta como a melhoria na mobilidade urbana, a qualidade de vida das pessoas a redução dos impactos ambientais dentre outros, os quais vão ao encontro dos pilares do conceito de city logistics discutidos por Taniguchi et al. (2000).

Com relação ao campo acadêmico a oportunidade esta em explorar um tema atual e relevante no contexto das organizações públicas e privadas e, sobretudo a contribuição na geração de novos conhecimentos sobre esta temática. Constatou-se que são diversas as publicações que abordam o tema plataforma logística, principalmente trabalhos que tem como background as operações realizadas em países localizados na Europa e na Ásia. As plataformas logísticas nas diversas tipologias e características apresentadas neste trabalho demonstram uma tendência e aplicabilidade local e global, sejam estas no âmbito privado ou mesmo público. Neste sentido entende-se a oportunidade para o desenvolvimento de futuras pesquisas acadêmicas que abordem e discutam alguns aspectos relacionados a:

- Analisar os aspectos relacionados à governança das plataformas logísticas. A governança é composta por procedimentos associados à tomada de decisões, desempenho e controle das organizações, com o fornecimento de estrutura para dar uma direção geral para a organização e para satisfazer expectativas razoáveis da prestação de contas para os que estão dentro ou são externos a própria organização (Albers, 2005; Peck et al. 2004). Outro ponto a destacar é que a governança, seja ela corporativa ou pública, envolve a relação entre diferentes atores e agentes, os quais estabelecem entre si um elo de interesses por diferentes razões, e em face disto, é necessário que se tenha uma governança 
adequada aos objetivos propostos entre as partes envolvidas. Uma plataforma logística pode ser instalada em diferentes ambientes (cidades, regiões etc...) e compreendem também a relação dos stakeholders, o que torna necessário a utilização de indicadores de desempenho para a mensuração da performance da governança e gestão destes empreendimentos logísticos.

A utilização de uma revisão sistemática como metodologia de pesquisa, possibilitou aos pesquisadores a elaboração e desenvolvimento do conhecimento acerca do tema plataforma logística de uma forma estruturada, clara e objetiva. Foram localizados inicialmente 90 trabalhos publicados em periódicos científicos, sendo que 21 foram selecionados e objeto de um maior aprofundamento sobre o conteúdo que havia nestes mesmos trabalhos e continham uma relação com objetivo desta pesquisa.

Um ponto que pode se destacar com relação a metodologia empregada, é que através de uma sistematização da pesquisa o trabalho de análise das publicações pode ser realizado de forma focada o que contribuiu para o resultado positivo dos pesquisadores na busca dos objetivos propostos. Entende-se que os objetivos propostos para este trabalho foram atingidos, uma vez que foi possível identificar as tipologias e características das plataformas logísticas, as quais foram apresentadas e discutidas anteriormente, possibilitando inclusive a descoberta de novas oportunidades de pesquisas sobre o tema.

Ficou evidenciando durante a pesquisa e análise dos trabalhos publicados que o tema plataforma logística é atual e relevante no âmbito das organizações privadas e públicas, pois atualmente se faz necessário um redesenho logístico para atendimento as demandas e a transposição das restrições atuais impostas a distribuição de produtos em centros urbanos ou mesmo para responder de forma dinâmica e eficiente aos diversos elos da cadeia de suprimentos. Entende-se também como contribuição do artigo, os resultados da pesquisa, os quais poderão ser utilizados como hipóteses para novas pesquisas e que possam tornar ainda mais robusto o conhecimento que se tem acerca das plataformas logísticas.

\section{Agradecimentos}

Agradecemos ao CNPq - Conselho Nacional de Desenvolvimento Científico e Tecnológico - pelo apoio durante a realização desta pesquisa. 


\section{Referências}

Abrahamsson, M., Aldin, N. e Stahre, F. (2003) Logistics platforms for improved strategic flexibility. International Journal of Logistics Research and Applications, vol. 6, n. 3, pp. 85-106.

Albers, S. (2005) The design of alliance governance systems. Köln: Kölner Wissenschaftsverlag.

Aldin, N. e Stahre, F. (2003) Electronic commerce, marketing channels and logistics platforms - a wholesaler perspective. European Journal of Operational Research, vol. 144, n. 2, pp. 270-279.

Ballis, A. e Mavrotas, G. (2007) Freight village design using the multicriteria method PROMETHEE. Operational Research, vol. 7, n. 2, pp. 213-231.

Biolchini, J., Mian, P., Natali, A.; Conte, T. e Travassos, G. (2007) Scientific research ontology to support systematic review in software engineering. Advanced Engineering Informatics, vol. 21, n. 2, pp. 133-151.

Clarke, M. Cochrane Reviewers' Handbook 4.1. Review Manager (RevMan). Oxford, England: The Cochrane Collaboration, (2001). Disponível em: www.cochrane.dk. Acesso em março de 2011.

Cambra-Fierro, J. e Ruiz-Benitez, R. (2009) "Advantages of intermodal logistics platforms: insights from a Spanish platform". Supply Chain Management: An International Journal, vol. 14, n. 6, pp. 418- 421.

Campolongo, M., Morandi, Corinna. e Mariotti, I. (2010) La piattaforma logistica di Leixões, Portogallo, e il suo território. Journal of Land Use. Mobility and Environment, vol. 3, n. 2, pp. 65-72.

Crainic, T. G., Ricciardi, N. e Storchi, G. (2004) Advanced freight transportation systems for congested urban areas. Transportation Research Part C: Emerging Technologies, vol. 12, n. 2, pp. 119-137.

Dias, J. C. Q., Calado, J. M. F., Osório, A. L. e Morgado, L. F. (2009) RFID together with multi-agent systems to control global value chains. Annual Reviews in Control, vol. 33, n. 2, pp. 185-195.

Gajsek, B., Lipicnik, M. e Simenc, M. (2012) The logistics platform disambiguation. Research in Logistics \& Production, vol. 1, n. 1, pp. 69-80.

Hesse, M. e Rodrigue, J. (2004) The transport geography of logistics and freight distribution. Journal of Transport Geography, vol. 12, n. 3, pp. 171-184.

Iannone, F. (2012) The private and social cost efficiency of port hinterland container distribution through a regional logistics system. Transportation Research Part A: Policy and Practice, vol. 46, n. 9, pp. 1424-1448.

Konings, J. W. (1996) Integrated centres for the transshipment, storage, collection and distribution of goods: A survey of the possibilities for a high-quality intermodal transport concept. Transport Policy, vol. 3, n. 1/2, pp. 3-11.

Lu, C. (2003) Market segment evaluation and international distribution centers. Transportation Research Part E: Logistics and Transportation Review, vol. 39, n. 1, pp. 49-60.

$\mathrm{Lu}, \mathrm{C}$. e Yang, C. (2007) An evaluation of the investment environment in international logistics zones: A Taiwanese manufacturer's perspective. International Journal of Production Economics, vol. 107, n. 1, pp. 279-300. 
McCalla, R. J., Slack, B. e Comtois, C. (2001) Intermodal Freight Terminals: Locality and Industrial Linkages. The Canadian Geographer, vol. 45, n. 3, pp. 404-413.

Marcucci, E. e Danielis, R. (2008) The potential demand for a urban freight consolidation centre. Transportation, vol. 35, n. 2, pp. 269-284.

Matera, R. R. T. (2012) O desafio logístico na implantação de um aeroporto indústria no Brasil. Journal of Transport Literature, vol. 6, n. 4, pp. 190-214.

Mazzarino, M. (2012) Strategic scenarios of global logistics: what lies ahead for Europe? European Transport Research Review, vol. 4, n. 1, pp. 1-18.

Meidute, I. (2007) Economical evaluation of logistics centres establishment. Transport, vol. 22, n. 2, pp. 111-1117.

Nilesh, A., Yang, M., Duin, J. e Tavasszy, L. (2012) GenCLOn: An ontology for city logistics. Expert Systems with Applications, vol. 39, n. 15, pp. 11944-11960.

Notteboom, T. E. e Rodrigue, J. P. (2005) Port Regionalization: Towards a New Phase in Port Development. Maritime Policy and Management, vol. 32, n. 3,pp. 297-313.

Peck, E., Six, P., Glasby, J. e Skelcher, C. (2004) "Governance and Partnerships". Journal of Integrated Care, vol. 12, n. 4, pg. 3-8.

Pettit, S. J. e Beresford, A. K. C. (2009) Port development: from gateways to logistics hubs. Maritime Policy \& Management, vol. 36, n. 3, pp. 253-267.

Porter, M. E. (2000) Economic Development: Local Clusters in a Global Economy. Economic Development Quarterly, vol. 14, n. 1, pp. 15-34.

Regan, A. C. e Golob, T. F. (2005) Trucking industry demand for urban shared use freight terminals. Transportation, vol. 32, n. 1, pp. 23-36.

Rimienè, K. e Grundey, D. (2007) Logistics Centre Concept through Evolution and Definition. Engineering Economics, vol. 4, n. 1, pp. 87-95.

Russo, F. e Comi, A. (2011) A model system for the ex-ante assessment of city logistics measures. Research in Transportation Economics, vol. 31, n. 1, pp. 81-87.

Santos Júnior, J. B. S., Lima Júnior, O. F., Novaes, A. G. e Scholz-reiter, B. (2011) A comparative analysis of supply network risk management techniques based on systematic literature review. Anais do XXV Congresso de Pesquisa e Ensino em Transportes, ANPET, Belo Horizonte.

Soni, G. e Kodali, R. (2011) A critical analysis of supply chain management content in empirical research. Business Process Management Journal, vol. 17, n. 2, pp. 238-266.

Stathopoulosa, A., Valeria, E. e Marcuccib, E. (2012) Stakeholder reactions to urban freight policy innovation. Journal of Transport Geography, vol. 22, n. 1, pp. 34-45.

Tang, J., Tang, L. e Wang, X. (2012) Solution method for the location planning problem of logistics park with variable capacity. Computers \& Operations Research, vol. 40, n. 1, pp. 406-417.

Taniguchi, E. e Van Der Heijden, R. E. (2000) An Evaluation Methodology for City Logistics. Transport Reviews, v. 20, n. 1, pp. 65-90.

Tranfield, D., Deyer, D. e Smart, P. (2003) Towards a Methodology for Developing EvidenceInformed Management Knowledge by Means of Systematic Review. British Journal of Management, vol. 14, n.3, pp. 207-202.

Trappey, C. V., Linb, G. Y. P., Trappey, A. J. C., Liud, C. S. e Leed, W. T. (2011) Deriving industrial logistics hub reference models for manufacturing based economies. Expert Systems with Applications, vol. 38, n. 2, pp. 1223-1232. 
Tsamboulas, D. e Dimitropoulos, I. (1999) Appraisal of investments in European nodal centres for goods - freight villages: A comparative analysis. Transportation, vol.26, n. 4, pp. 381-398.

Tsamboulas, D. A. e Kapros, S. (2003) Freight Village Evaluation Under Uncertainty With Public And Private Financing. Transport Policy, vol. 10, n. 2, pp. 141-156.

Wagner, T. (2010) Regional traffic impacts of logistics-related land use. Transport Policy, vol. 17 , n. 4, pp $224-229$. 